\title{
The Cognitive Limits to Economic Cluster Formation
}

\author{
Michael C. Carrol and Mark C. Zeller
}

\begin{abstract}
Michael C. Carroll, Center for Regional Development and Department of Economics, Bowling Green State University, USA (mcarrol@bgnet.bgsu.edu)
\end{abstract}

Mark C. Zeller, Center for Regional Development, Bowling Green State University, USA (zellerm@bgsu.edu)

\begin{abstract}
There has been increasing interest in the social dimensions of economic clusters. The literature now includes select examples of social network analysis plus an extensive discussion of learning regions. Unfortunately, much of this work treats the network as the primary unit of analysis. It may be that network attributes such as density, centrality, and power are primarily dependent on human limitations and not instituted factors. In other words, a human's limited ability to process information may be a better determinant of cluster success than economic or network theory. The purpose of this paper is to highlight human limits in cluster formation. To do this, we draw on recent developments in the cognitive psychology and communications literatures. We explain that many of the factors that lead to underperforming cluster policies are the result of a human's inability to develop and sustain a large number of social interactions. Any cluster policy must be cognizant of such limitations and carefully address these limits in the formation of the initial strategy.
\end{abstract}

Keywords: cluster theory, network attributes, cognitive psychology

\section{Introduction}

Economic clusters have become ubiquitous in the developer's toolbox. Economic cluster projects can be found in most developed regions and are currently the policy of choice for many. While there are a number of development activities done in the name of clusters, there is general agreement that the benefit of cluster policy stems from synergies generated by the interaction of co-located firms. It should be recognized that this interaction is fundamentally human interaction - augmented by formal and informal institutions - and is therefore subject to human limitations.

The purpose of this paper is to highlight human limits in cluster formation. To do this, we draw on recent developments in the cognitive psychology and communications literatures. We find that many of the factors that lead to underperforming cluster policies are the result of a human's inability to develop and sustain a large number of social interactions. Any cluster policy must be cognizant of such limitations and carefully address these limits in the formation of the initial strategy. The first section of this paper provides a brief overview of cluster dynamics. It defines what collaborative behaviours are necessary for cluster strategies to work. Section two, explores the boundaries of economic agent's behaviours. Section three looks at the cognitive limits of human memory and section four details an agent's cognitive capacity that may limit membership in social groups. 


\section{Cluster Dynamics: The Fundamentals}

Cluster-based economic development (CBED) is a popular targeting strategy. It is an extension of agglomeration economics. The neo-Marshallian definition currently in vogue was offered by Michael Porter (1998): Clusters are geographic concentrations of interconnected companies, suppliers, service providers, firms in related industries, and associated institutions (for example universities, standards agencies, and trade associations) in particular fields that compete but also co-operate.

CBED seeks to build groups of dependent businesses that are strengthened by proximate location. Unfortunately, the concept of a cluster has expanded and taken on multiple meanings. The term is no longer limited to external economies. It now is used to describe a wide variety of firm behavioural characteristics and policy prescriptions. Martin and Sunley (2003) offer a list of 10 distinct definitions that have appeared in the economics, policy, and geography literatures. The term cluster has tended to morph with the presupposition that clusters create innovations, represent 'learning regions', and increase the transference of knowledge simply because the firms are co-located. Often, little or no thought is given to the enabling institutions that underpin clustered firms. Also and particularly disturbing to institutionalists, unequal power relationships between firms are ignored. "Issues of inter-firm subordination, exploitation and control have dropped out of the cluster lexicon” (Taylor and Plummer 2003: 240).

As the cluster concept lost its rigor, its popularity as a development tool has grown. Practitioners rushed to identify local clusters and target them as growth poles. It is not uncommon to see clusters being built around nothing more than a locality's aspiration. So if they want to be like Silicon Valley, they identify groups of businesses and refer to them as an 'IT cluster'. The increasing misuse of cluster development programmes has prompted Martin and Sunley (2003: 5) to suggest that the "cluster concept should carry a public policy health warning”. Successful cluster programmes usually include more than an analysis of which industries attract one another. If a region is to enjoy economic vitality, the local firms must be engaged in the region's development strategy. Without this active participation of local enterprises, CBED policy will never reach its full potential. As new firms develop in a region, they still need to be integrated into the existing industrial web. Even branch plants that produce components for a parent company rely on local social and economic networks for operation. In short, the co-location of firms in a cluster presents an opportunity for external economies, but it is the depth of social capital that enables the supradevelopment activity. An important characteristic of a successful cluster is the emphasis on social networks. Economic clusters are made up of multiple networked social organizations. Cluster formation increases the potential of relational contacts for economic actors (Burt and Ronchi 2007). Operational clusters have formal and informal networks that operate for the economic benefit of the cluster participants and the region. An efficient cluster strategy ensures that economic activity is embedded in the social fabric of the region. A comprehensive CBED strategy is a network-driven approach that stresses communication and cooperation between firms in the cluster core industry; the core's local supply chain; and local government and support institutions such as universities, think tanks, and development agencies. It works with existing market forces, anticipating and exploiting business opportunities to promote growth faster and more completely than in the absence of a cluster strategy. CBED starts with a rigorous examination of the local economic structure and identifies opportunities for mutual gain from collaboration. CBED is an active development strategy rather than a grouping of 
industries. It will not reach its full potential without support from the local public sector, regional economic development agencies, and the existing private sector. Developing the necessary social capital is a challenge in implementing a CBED policy. The real gain is not from changing market forces but in reinforcing them and accelerating change beyond what would be possible without the cluster policy.

CBED did not enjoy the necessary refinements of a thorough academic debate. The evaluation of cluster-based development is an example of how 'faddish' words or ideas have captured the attention of economic development officials and academics. Yet, as with most fads, the idea has some merit. The word has been applied willy-nilly too many development problems regardless of social circumstances, in a feeble attempt to turn CBED into a 'one-size-fits-all' policy (Taylor 2005). Consequently, it has been very easy to criticize most CBED efforts as lacking substance or being less than effective (Martin \& Sunley 2003). In truth, CBED has been properly applied in only a handful of cases. Furthermore, most of the recent academic literature has focused on the technical aspects of identifying clusters (Feser and Sweeney 2002) and not on the philosophical underpinnings of economic clustering.

If clustering develops agglomeration gains beyond what is typically achieved by passive economies of scale generated by co-located firms, then it is a result of intellectual interpretation of the local conditions ${ }^{1}$. It is the capacity of the individual economic agent that determines this advantage. No model can be based on specific advantages of an individual. We can however, incorporate cognitive limits of humans into models of economic interaction. The balance of this paper attempts to highlight this possibility.

\section{Social and Economic Development from an Individual Agent Perspective}

Evidence within network studies overwhelmingly supports homophilius characteristics linking individuals within social structures (Rogers and Kincaid, 1981). These similarities enable and constrain an individual's membership in social groups and network structures, and correlate with an individual's connectedness, frequency of interaction and information flow. The closer in geographic proximity and social characteristics, the more likely there will be interaction (McPherson et al. 2001).

In contrast, individual differences and geographic distance may account for social isolates, lack of cohesiveness and density among members, weak links, interaction frequency decay, and non-membership among network social structures (Burt, 2004). Chance encounters and life paths may not be as random as once thought, but rather, a result of social similarities and proximities of individuals with corresponding socio demographic characteristics (Bandura 1982, Watts 2004, Kochen 1989). "The nature of individual ties may be more important than the nature of networks" (Wellman 1999: 25). However, personal effort and capability to maintain relationship ties sensitive to social differences and distance must develop. The benefit of social support, reciprocity, and trust may not occur from the density of group pressures, but the effectiveness of personal investment in individual relationship ties (Plickert, Cote, and Wellman 2007). Research supports that individual independence and choice of interaction or communicative behaviour extends far beyond the structure of the community, neighbourhood and work organizations (Mok et al. 2007).

\footnotetext{
${ }^{1}$ This assumes there are no resource specific advantages related to a location.
} 


\section{Interactions, Cognitive Limitations and Working Memory}

Economic cluster development research findings support economic advantages for mobile individuals as human capital initiating and maintaining personal career ties and relationships within similar career paths and like industries across geographic distance. The mobility of the human intellectual capital is a major factor for cluster development (Casper and Murray 2005, Casper 2007).

Human perception and mental concepts, memory, reasoning, decision making, information gathering, problem solving, language acquisition and use may be defined as cognition (Goldstein 2008). A complex society requires that humans utilize institutions to acquire education, act as repositories for knowledge while assisting limited individual cognitive reasoning and social interaction processes (Anderson 1983, 2005). Because of this complex society and social interaction, knowledge, and the individual's limited capacity of memory, research emphasizes the need for social institutions to manage the communication processes and knowledge distribution for individual economic transactions. Knowledge and cognition play a central role in today's complex economic society (Martens 2004). "Cognitive devices that achieve more compression of information and more efficient communication of these compressed packages constitute an economic advantage" (Martens 2004: 55-56).

Management of knowledge and human cognition are linked. Individuals use her or his senses to acquire information, and then use the information to create mental models. "When confronted with a highly complex world, the mind constructs a simple mental model of reality and tries to work within that model. The model may have weaknesses, but the individual will try to behave rationally within the constraints or boundaries of that model” (Dalkir 2005: 61). Through the use of these mental models, humans process and organize information into bounded rational behaviour and knowledgeable actions developing personalized mental concepts such as schema, cognitive maps, and scripts (Dalkir 2005).

In the seminal work of Miller (1956a), cognitive limits are delimited to seven plus or minus two absolute judgments. These cognitive limitations, specifically human capacity limits termed elements, process information in immediate, short-term working memory. Miller finds that an individual can remember more items if the items are coded or chunked ${ }^{2}$. For example, an individual recalls learned patterns, such as a recognized sequence of words or identified groups of objects from memory and past experiences.

An individual's perception is influenced by stored information in long-term memory brought forth to working memory, greatly increasing working memory. More recent research termed the psychological cognitive revolution (Miller 2003a) emphasizes that individuals are information processors. Applied cognitive psychology and instructional design maintains an individual's processing ability is limited, and individuals may expand and develop expertise through redundancy by applying learning methods.

\section{Boundaries of Rationality, Cognitive Capacity and Limited Membership}

Heuristics are learned procedures (usually socially constructed) for approximating, that humans use to make judgments or inferences drawing from their schemas and scripts (Gigerenzer and Todd 1999). “Cognitive abilities are quite limited...the decision

\footnotetext{
${ }^{2}$ Researchers support Miller's (1956b) inquiry that information and memory may be retained by association and grouping with other mental experiences (Tulving and Craik, 2000). That is, if a set of items have been structured or associated, recall capacity is greatly increased.
} 
making behaviour of human beings cannot conform to the ideal of full rationality" (Selten 2001: 14). These inferences are made from the learned heuristic behaviours that individuals rely on through their collective social groups and formal institutions to make timely decisions (Todd 2001). Human beings use learned heuristic processes from experience for decision-making within social exchange between similar and diverse interests among individuals, foreseen by Simon (1957). The use of these heuristics, originally identified as bounded rationality by Simon, is the behaviour of an individual's similarities and differences that challenge institutional structures and boundaries with the individual's tensions of change. That is, the structured boundaries of society defined by mental and agreed upon social constructions (albeit in vague terms) generating human institutional and behavioural outcomes.

Boundaries of rationality for an individual emerge upon interactions with other individuals within network structures. Behavioural roles and network structure positions within organizations create interaction activities, generating more divergent activities by exchanging knowledge and information. Individuals are limited by the bounds of each organization's context (Bathelt et al. 2004). Individuals' actions are strategic to their own interests while playing social roles and may be layered within and overlap other social structures while seeking identity and control. Therefore, to achieve goals and aspirations, one must interact (White 1992, 2007).

Individual interaction limits within a group constrain communicative behaviour. With every additional member to the group, a more than symmetrical increase in potential relationship reciprocal interactions occur (Kephart 1950). Increased contacts and the resulting complexity of relationships will increase cognitive overload, reaching cognitive capacity limits of individuals' mental perspectives (Stiller and Dunbar 2007). An actor's negative understanding and communication challenge coherent information flow, resulting in negative social capital (Carroll and Stanfield 2003, Burt and Ronchi 2007).

Information overload may limit cognitive information processing due to the number of elements used between sender and receiver (Miller 1960). Factors necessary for individual membership behaviour within collective group structures (institutions) require cognitive capacity. Learned heuristic models, often called schemata, for behavioural interaction and group membership may require higher or lower cognitive element use. That is, if schemata are learned, there is a need for fewer elements of working or short-term cognitive capacity (van Merrienboer and Sweller 2005). For membership, groups may require high element characteristics for cohesiveness, density, and closed boundaries or low density, low cohesiveness, and open boundaries, and sometimes a multiplexity of these characteristics. Understanding and developing cognitive social skills (schemata and scripts) may be the limiting factor for most individuals (Todd and Gigerenzer 2007).

Research evidence on the cognitive abilities or constraints of one individual's capacity of human social group size is estimated at 150 . That is, the number of individual one individual can maintain as social possibilities for interaction along with the elements of information for processing similarities and differences are limited by individual cognition. The cognition capacity may be sustained at a given intensity of relationships. More intense relationships are supported by smaller groups of approximately 50 (Hill and Dunbar 2003). The patterns of group size of 50 and 150 profile both the constraints of human cognitive information processing capacity and the evolutionary development of human cognitive information processing capacity (Dunbar, 
Barrett and Lycett 2005). Dunbar's research describes the development of individual cognitive abilities as the result of benefits of social interaction and shared cooperation within group membership, sometimes collaborative and cooperative, and more often manipulative to achieve individual goals (Dunbar 1998, 2003).

An individual's cognitive limits, due to the increasing complexity of interactions, restrict an individual's group network size. Considering the similarities and differences of individuals within a group, group efficiency improves goal attainment of collective action because of division of labour, roles played, and collective knowledge (Kudo and Dunbar 2001, Lehmann et al. 2007). For example, an individual's long-term experiences (sometimes called mental images) and various types of reciprocity allow for an individual to construct temporal relationships such as the development of trust or distrust, development of positive or negative social capital, and motivation to resist or interact with others (Dunbar 1996, 2004). These mental images (many times episodic experiences) may be brought forward into working memory as chunks for rapid decision making. Recent research modelling of cognitive architecture underscores chunking. The power of cognition is found in the use of associative long-term memory rather than abundant short-term buffers (Jonides et al. 2008, Anderson et al. 2004). Short-term memory, limited in focus of attention when associated with long-term memories, does not seem to pose functional problems in cognitive processing (Jonides et al. 2008). Examples of chunking mechanisms utilized in educational guidance support this experience (Gobet 2005).

The attractiveness of a group or structured network to an individual, and the individual's choice to be a member, is dependent on the concurrence of the collective structure and the individual's goals (Napier and Gershenfeld 1999, Oyserman 2003). Economic cluster formation increases the potential for the number of relational contacts. These relational contacts increase the complexity of information flow, increasing the cognitive load of individual actors. The network structure for knowledge dissemination, maintenance and accumulation must be defined for each individual actor's choice as a member (Pinch et al. 2003). The cognitive passage from an individual's own participation and interests to achieve her or his own goals within a group is best understood through the use of the concept called theory of mind. "Human capacity for reasoning about the mental causes for action is called theory of mind" (Saxe et al. 2004: 88). An individual's own goals with a group leap to a group collective's goals, initiating group interaction and resultant relationships among other groups. This individual and social cognition is best understood in theory of mind through the concept of an individual's perceptual mentalization of other's intentions. Neural research, through the use of brain imaging, infers the mentalization of intentions (Frith and Frith 1999, 2006). Shared attention is understood as communicative intent, or the group's reasoning shared mentalizations to interact for group goals (Sperber and Wilson 1995).

By associating these mentalizations (chunking) from long-term memory, individuals may interact and participate in multiple group network structures. The reduced cognitive capacity without possible cognitive overload may be accomplished by pre-learned, individual mental representations of information as knowledge content (Saxe 2006). For example, institutions act as repositories of knowledge and representative agencies for social economic development. Shared attention through interpersonal contacts is the best way to transplant innovative new knowledge (Rogers 2003, Wolfe and Gertler 2004). Institutionalized group structures allow for formal and informal codes of membership behaviour to be subjectively accepted, with possibly 
little participation other than benefits from the group. Individuals obtain organizational network benefits by means of membership (Olson 1971), such as membership in a large club, church, union, or trade organization. However, the demands of keeping track of the complexity of informational processing with relationship characteristics in interpersonal contacts are still limited by individual cognitive social calculations. Human relationships and organization structures are limited by personal levels of intentionality and memory, ranging from between six and 20 contacts (individuals) (Dunbar and Spoors 1995, Hill and Dunbar 2003, Stiller and Dunbar 2007).

\section{Conclusion}

There is a large literature on economic agency. Unfortunately, much of it is from a neoclassical economics perspective and little directly addresses cognitive limits of human behaviour. Determining the behaviour of an economic agent is more complex that assuming profit maximization. This complexity increases when designing a cluster policy that encourages (relies on) the interaction of economic agents. Structures (strategies) need to be developed for the cluster, creating a centralized, project oriented information flow. Fragmented economic development activity ensues without coordinated cluster formation.

This paper has attempted to delineate issues related to the human limits of economic behaviour. Specifically it explored limits in group behaviour and explored how an individual's behaviour in groups can be bounded by their ability to process information. Cluster advantages develop through centralized knowledge sharing. The individual actor's limits for relationship and memory must be taken into consideration when building network structures for centralized knowledge sharing. Because of the limits, the cluster's network structure must establish the representative agent's position, such as methods for information dissemination, technology sharing, and physical infrastructure. These limits have significant implications for the design of cluster policy - a policy designed to encourage information flows. Individuals are linked within social structures, but interactions and relationships between individuals are influenced by knowledge, cognitive limitations, and individual similarities and differences. As stated earlier, the demands of keeping track of the complexity of informational processing with relationship characteristics in interpersonal contacts are still limited by individual cognitive social calculations.

\section{References}

Anderson, J.R. 2005. Cognitive Psychology and Its Implications. New York: Worth.

Anderson, J.R. 1983. The Architecture of Cognition. Cambridge, MA: Harvard University Press.

Anderson, J.R., Bothell, D., Byrne, M.D., Douglass, S., Lebier, C. and Qin, Y. 2004. An integrated theory of the mind. Psychological Review, 111(4), 1036-1060.

Bandura, A. 1982. The psychology of chance encounters and life paths. The American Psychologist, 37(7), 747-755.

Bathelt, H., Malmberg, A., and Maskell, P. 2004. Clusters and knowledge: Local buzz, global pipelines and the process of knowledge creation. Progress in Human Geography, 29(1), 31-56.

Burt, R.S. 2004. Structural holes and good ideas. AJS Review, 110(2), 349-399.

Burt, R.S. and Ronchi, D. 2007. Teaching executives to see social capital: Results from a field experiment. Social Science Research, 36(3), 1156-1183. 
Carroll, M. and Stanfield, J.R. 2003. Social capital, Karl Polanyi and American Social and Institutional Economics. Journal of Economic Issues, 37, 2003.

Casper, S. 2007. How do technology clusters emerge and become sustainable? Social network formation and inter-firm mobility within the San Diego biotechnology cluster. Research Policy, 36, 438-455.

Casper, S. and Murray, F. 2005. Careers and clusters: Analyzing the career network dynamic of biotechnology clusters. Journal of Engineering and Technology Management, 22, 51-74.

Dalkir, K. 2005. Knowledge Management in Theory and Practice. Amsterdam: Elsevier.

Dunbar, R.I.M. 2004. The Human Story: A New History of Mankind's Evolution. Chatham, Kent/ England: Faber and Faber.

Dunbar, R.I.M 2003. Evolution of the social brain. Science, 302(5648), 1160-1161.

Dunbar, R.I.M. 1996. Grooming, Gossip, and the Evolution of Language. Cambridge, MA: Harvard University Press.

Dunbar, R.I.M. 1998. The social brain hypothesis. Evolutionary Anthropology, 6, 178-190.

Dunbar, R.I.M., Barrett, L, and Lycett, J. 2005. Evolutionary Psychology: A Beginner's Guide. Oxford: Oneworld.

Dunbar, R.I.M. and Spoors, M. 1995. Social networks, support cliques and kinship. Human Nature, 6(3), 273-290.

Feser, E.J. and Sweeney, S.H. 2002. Theory, methods, and a cross-metropolitan comparison of business clusters, in Industrial Location Economics, edited by P. McCann. Cheltenham, UK: Edward Elgar, 222-259.

Frith, C.D. and Frith, U. 2006. The neural basis of mentalizing. Neuron, 50, 531-534.

Frith, C.D. and Frith, U. 1999. Interacting minds: A biological basis. Science, 286(5445), 1692-1696.

Gigerenzer, G. and Todd, P.M. 1999. Simple Heuristics that Make Us Smart. New York: Oxford University Press.

Gobet, F. 2005. Chunking models of expertise: Implications for education. Applied Cognitive Psychology, 19, 183-204.

Goldstein, E.B. 2008. Cognitive Psychology: Connecting Mind, Research and Everyday Experience. Belmont, CA: Thomson Wadsworth.

Grusec, J.E. and Hastings, P.D. (eds.). 2007. Handbook of Socialization: Theory and Research. New York: Guilford Press.

Hill, R.A. and Dunbar, R.I.M. 2003. Social network size in humans. Human Nature, 14(1), 53-72.

Jonides, J., Lewis, R.L., Nee, D.E., Lustig, C.A., Berman, M.G. and Moore, K.S. 2008. The mind and brain of short-term memory. Annual Review of Psychology, 59, 193-224.

Kephart, W.M. 1950. A quantitative analysis of intragroup relationships. The American Journal of Sociology, 55 (6), 544-549.

Kochen, M. (ed.) 1989. The Small World. Norwood, NJ: Ablex.

Kudo, H. and Dunbar, R.I.M. 2001. Neocortex size and social network size in primates. Animal Behaviour, 62, 711-722.

Lehmann, J., Korstjens, A.H. and Dunbar, R.I.M. 2007. Group size, grooming and social cohesion in primates. Animal Behaviour, 74, 1617-1629. 
Martens, B. 2004. The Cognitive Mechanics of Economic Development and Institutional Change. New York: Routledge.

Martin, R. and Sunley, P. 2003. Deconstructing clusters: Chaotic concept or policy panacea? Journal of Economic Geography, 3, 5-35.

McPherson, M., Smith-Lovin, L. and Cook, J.M. 2001. Birds of a feather: Homophily in social networks. Annual Review of Sociology, 27, 415-444.

Miller, G.A. 2003a. The cognitive revolution: A historical perspective. Trends in Cognitive Science, 7(3), 141-144.

Miller, G.A. 1956a. The magical number seven, plus or minus two: Some limits on our capacity for processing information. The Psychological Review, 63(2), 81-97.

Miller, G.A. 1956b. Information and memory. Scientific American, 195(2), 42-46.

Miller, J.G. 1960. Information input overload and psychopathology. American Journal of Psychiatry, 116, 695-704.

Mok, D., Wellman, B. and Basu, R. 2007. Did distance matter before the Internet? Interpersonal contact and support in the 1970s. Social Networks, 29(3), 430-461.

Napier, R.W. and Gershenfeld, M.K. 1999. Groups: Theory and practice. Boston: Houghton Mifflin.

Olson, M. 1971. The Logic of Collective Action. Cambridge, MA: Harvard University Press.

Oyserman, D. 2003. Self-concept and identity, in Blackwell Handbook of Social Psychology: Intraindividual Processes, edited by A. Tesser and N. Schwarz. Malden, MA: Blackwell, 499-517.

Paas, F., Renkl, A. and Sweller, J. 2003. Cognitive load theory and instructional design: Recent developments. Educational Psychologist, 38(1), 1-4.

Pinch, S., Henry, N., Jenkins and Tallman, S. 2003. From 'industrial districts' to 'knowledge clusters': A model of knowledge dissemination and competitive advantage in industrial agglomerations. Journal of Economic Geography, 3(4), 373-388.

Plickert, G., Cote, R.R. and Wellman, B. 2007. It's not who you know, it's how you know them: Who exchanges what with whom? Social Networks, 29, 405-429.

Porter, M.E. 1998. On Competition. Boston: Harvard Business School Press.

Rogers, E.M. 2003. Diffusion of Innovations. New York: Free Press.

Rogers, E.M. and Kincaid, D. L. 1981. Communication Networks: Toward a New Paradigm for Research. New York: Free Press.

Saxe, R. 2006. Uniquely human social cognition. Current Opinion in Neurobiology, 16, 235-239.

Saxe, R., Carey, S. and Kanwisher, N. 2004. Understanding other minds: Linking developmental psychology and functional neuroimaging. Annual Review of Psychology, 55, 87-124.

Selten, R. 2001. What is bounded rationality?, in Bounded Rationality: The Adaptive Toolbox, edited by G. Gigerenzer and R. Selten. Cambridge, MA: MIT Press, 13-36.

Simon, H.A. 1957. Models of Man: Social and Rational. Mathematical Essays on Rational Human Behavior in a Social Setting. New York: Garland.

Sperber, D. and Wilson, D. 1995. Relevance: Communication and Cognition. Malden, MA: Blackwell.

Stiller, J. and Dunbar, R.I.M. 2007. Perspective-taking and memory capacity predict social network size. Social Networks, 29, 93-104. 
Sweller, J. 2004. Instructional design consequences of an analogy between evolution by natural selection and human cognitive architecture. Instructional Science, 32, 931.

Sweller, J. 2003. Evolution of human cognitive architecture, in The psychology of Learning and Motivation: Advances in Research and Theory, edited by B.H. Ross. Boston: Academic Press, 215-266.

Taylor, M. 2005. 'Clusters': The Mesmerizing Mantra. Paper for the IGU meeting, commission on the dynamics of economic space, Toledo, $\mathrm{OH}$, August, 2-5.

Taylor, M. and Plummer, P. 2003. Drivers of local growth: Ideologies, ambiguities and policies. Australian Journal of Regional Studies, 9(3), 235-257.

Todd, P.M. 2001. Fast and frugal heuristics for environmentally bounded minds, in Bounded rationality: The Adaptive Toolbox, edited by G. Gigerenzer and R. Selten. Cambridge, MA: MIT Press, 51-70.

Todd, P.M. and Gigerenzer, G. 2007. Mechanisms of ecological rationality: Heuristics and environments that make us smart, in The Oxford Handbook of Evolutionary Psychology, edited by R.I.M. Dunbar and L. Barrett. New York: Oxford University Press, 197-210.

Tulving, E. and Craik, F.I.M. (eds.). 2000. The Oxford Handbook of Memory. New York: Oxford University Press.

van Merrienboer, J.J.G. and Sweller, J. 2005. Cognitive load theory and complex learning: Recent developments and future directions. Educational Psychology Review, 17(2), 147-178.

Watts, D.J. 2004. Small Worlds: The Dynamics of Networks Between Order and Randomness. Princeton, NJ: Princeton University Press.

Wellman, B. (ed.) 1999. Networks in the Global Village: Life in Contemporary Communities. Boulder, CO: Westview Press.

White , H.C. 1992. Identity and Control: A Structural Theory of Social Action. Princeton University Press.

White, H.C. 2007. Instituting society, our mirage. European Journal of Social Theory, 10(2), 194-199.

Wolfe, D.A. and Gertler, M.S. 2004. Clusters from the inside and out: Local dynamics and global linkages. Urban Studies, 41(5/6), 1071-1093. 